\title{
Unusual Occurrence of Salmonella Mikawasima in 2012-2013 in the Czech Republic: Part of a Multistate Outbreak?
}

\author{
PETRA MYŠKOVÁ and RENÁTA KARPÍŠKOVÁ \\ Department of Bacteriology, Veterinary Research Institute, Brno, Czech Republic \\ Submitted 13 March 2014, revised 8 July 2014, accepted 15 July 2014
}

\begin{abstract}
An increased number of cases of salmonellosis caused by the rare serotype Mikawasima was noted in the years 2012 and 2013 in the Czech Republic. A potential on-going outbreak caused by this serotype in European countries has also been reported. Altogether 14 human and 1 environmental isolates from the year 2012 and 11 human isolates from the year 2013 from different locations of the Czech Republic were sent to our laboratory for typing. Macrorestriction analysis together with antimicrobial susceptibility testing and PCR for ESBL and plasmid-mediated quinolone resistance detection were performed to compare our isolates. Twenty-one isolates created two very similar clusters and 5 isolates had different profiles. Twenty-five isolates were fully susceptible to all agents used. One isolate showed resistance to 12 microbial agents and possessed $b l a_{\mathrm{TEM}}, b l a_{\mathrm{SHV}}, b l a_{\mathrm{OXA}}, b l a_{\mathrm{CTX}-\mathrm{M}}$ and $q n r \mathrm{~B}$ genes.
\end{abstract}

Ke y words: Salmonella, $\beta$-lactam resistance, multistate outbreak, quinolone resistance

Salmonellosis is still being reported as the second most common food-borne infection of bacterial origin. Salmonella enterica subsp. enterica serotype Enteritidis (S. Enteritidis) and S. enterica subsp. enterica serotype Typhimurium (S. Typhimurium) are the most prevalent serotypes. Nevertheless, cases and outbreaks caused by rare serotypes are occasionally reported. Lately, a major outbreak caused by serotype Stanley has been reported from the European Union (ECDC, 2012).

During the years 2012 (Myskova et al., 2013) and 2013, an unusual increase in the number of human cases caused by S. Mikawasima was noted in the Czech Republic. This serotype is considered rare in our country. Only one European outbreak caused by this serotype has been published so far (Synnott et al., 1993). In November 2013, ECDC stated that there was an increased prevalence in more than one European country (ECDC, 2013). Our aim was to compare macrorestriction profiles and resistances to antimicrobial agents of all isolates of this serotype reported in the Czech Republic in years 2012 and 2013 and to try to match the isolates to potential outbreak cases.

Altogether 14 human and 1 environmental isolates (waste water from sewage disposal plant) from the year 2012 and 11 human isolates from the year 2013 of Salmonella Mikawasima from 10 districts at different locations of the Czech Republic were isolated and sent to our laboratory for typing. All isolates were serotyped in the National reference laboratory for Salmonella in NIPH Prague and their antigenic formula was described as O:6, 7, 14 H1:y H2:e, n, z15.

Susceptibility to a panel of 18 antimicrobial agents was determined by the disk diffusion method according to the CLSI protocol using Mueller-Hinton agar (CLSI, 2012). The spectrum of the agents used and their concentrations were: A - ampicillin $(10 \mu \mathrm{g})$, Amc - ampicillin/clavulanic acid $(30 \mu \mathrm{g}), \mathrm{Ctx}-$ cefotaxime $(30 \mu \mathrm{g})$, C - chloramphenicol $(30 \mu \mathrm{g})$, Mem - meropenem $(10 \mu \mathrm{g})$, $\mathrm{S}$ - streptomycin $(10 \mu \mathrm{g}), \mathrm{K}$ - kanamycin $(30 \mu \mathrm{g}), \mathrm{Cn}$ - gentamicin $(10 \mu \mathrm{g}), \mathrm{N}$ - neomycin $(30 \mu \mathrm{g})$, Su - sulphonamides $(300 \mu \mathrm{g})$, Sxt - sulfamethoxazole/trimethoprim $(25 \mu \mathrm{g}), \mathrm{W}$ - trimethoprim $(5 \mu \mathrm{g}), \mathrm{Te}$ - tetracycline $(30 \mu \mathrm{g}), \mathrm{Na}$ - nalidixic acid $(30 \mu \mathrm{g}), \mathrm{Cip}$ - ciprofloxacin $(5 \mu \mathrm{g}), \mathrm{Enr}-$ enrofloxacin $(5 \mu \mathrm{g}), \mathrm{Ct}-$ colistin $(10 \mu \mathrm{g})$, Atm - aztreonam $(30 \mu \mathrm{g})$. Escherichia coli CCM 3954 was used as the control strain.

Polymerase Chain Reaction for the detection of $b l a_{\mathrm{TEM}}, b l a_{\mathrm{SHV}}, b l a_{\mathrm{OXA}}, b l a_{\mathrm{CTX}-\mathrm{M}}$ and $q n r \mathrm{~A}, q n r \mathrm{~B}$ and $q n r \mathrm{~S}$ was also performed (Briňas et al., 2002; Guerra et al., 2000; Lewis et al., 2007; Cattoir et al., 2007).

Pulsed-Field Gel Electrophoresis (PFGE) was performed according to the PulseNet protocol using XbaI enzyme and software BioNumerics version 5.1 for analysis (Ribot et al., 2006).

* Corresponding author: P. Myšková, Department of Bacteriology, Veterinary research institute, v.v.i., Hudcova 70, 62100 Brno, Czech Republic; phone: + 420 53331631, e-mail: myskova@vri.cz 


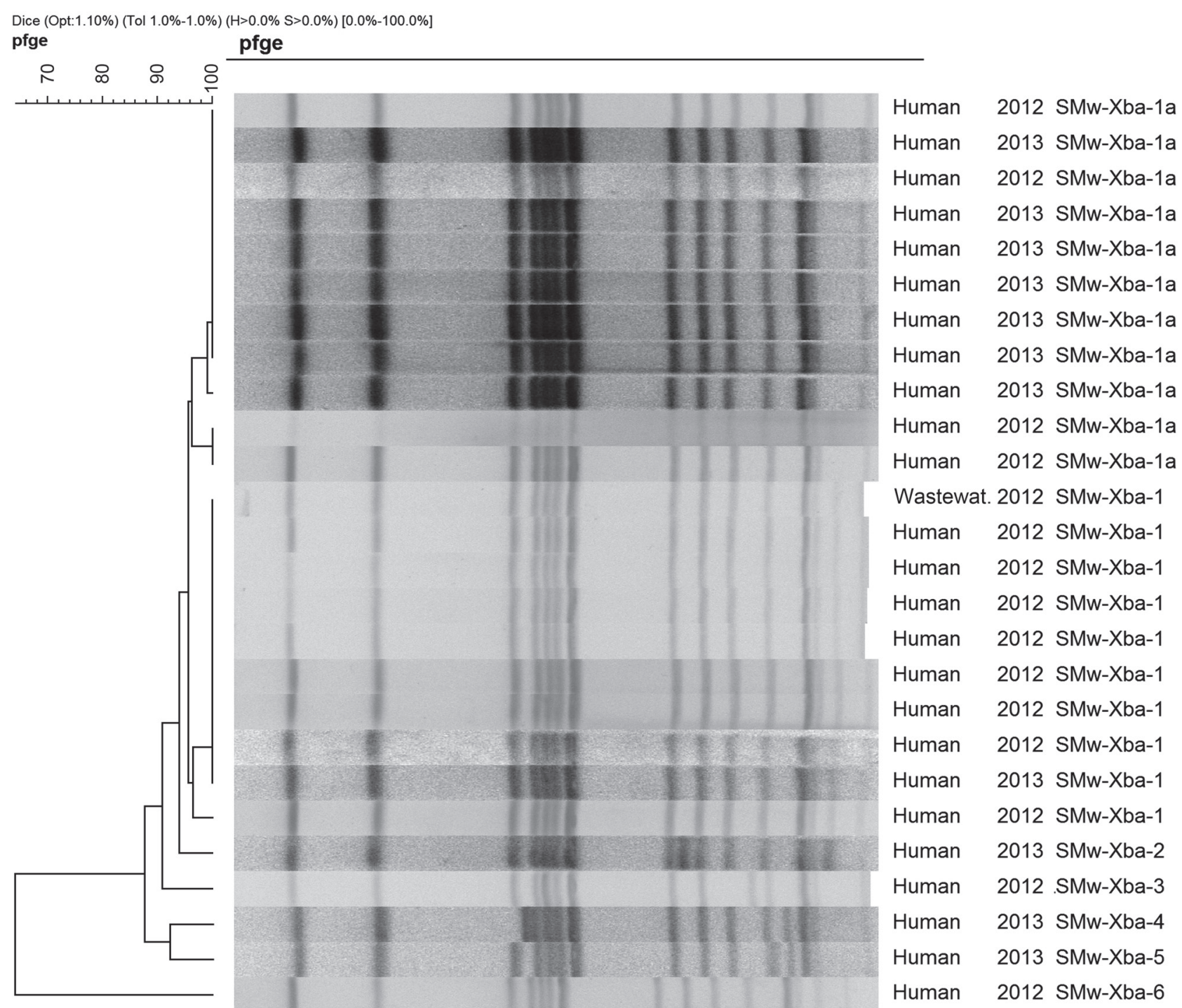

Fig. 1. Salmonella Mikawasima macrorestriction profiles

Twenty-five out of twenty-six isolates were susceptible to all tested antimicrobial agents. However, a human isolate from 2013 was discovered to be resistant to 12 agents (A/Ctx/C/S/K/Cn/Su/Sxt/W/Te/Na/Atm). This isolate carried genes $b l a_{\mathrm{TEM}}, b l a_{\mathrm{OXA}}, b l a_{\mathrm{CTX}-\mathrm{M}}$ and plasmid mediated qnrB.

Altogether six rather similar macrorestriction profiles (almost 90\% similarity) were detected (Fig. 1). Within the first major group (21 isolates) two subprofiles could be recognized ( $95 \%$ similarity), SMw-Xba-1 most typical for isolates from 2012 and SMw-Xba-1a most typical for isolates from 2013. There were five isolates with different profiles, two from 2012 (SMwXba-3, SMw-Xba-6) and three from 2013 (SMw-Xba-2, SMw-Xba-4, SMw-Xba-5). The environmental isolate from waste water shared the most common profile from 2012 (SMw-Xba-1). Most cases (37.5\%) belonged to patients of the age group $\geq 65$ years.

Czech isolates of the serotype Mikawasima from the years 2012 and 2013 showed great similarity apart from five human isolates. Moreover, our PFGE profiles matched profiles from other European countries (ECDC, 2013). Interestingly, the isolates with the outbreak profile were obtained in various and also distant areas of our country which also indicates the Czech Republic became a part of an outbreak of a greater extent. Unfortunately, no isolate of food origin was obtained. However, it is noteworthy that the majority of cases belonged to the adult age group. The isolate showing 12 antimicrobial agents resistance pattern and pulse profile SMw-Xba-2 isolated in 2013 from a longterm hospitalized elderly patient ( 83 years) without any travel history might have received a plasmid carrying resistance genes. Nevertheless, to confirm this hypothesis, a further examination is needed.

Apparently, there has been an on-going outbreak of salmonellosis in Europe caused by the rare serotype Mikawasima. It is important to find out how many countries have been affected and try to detect the source of the infection. 


\section{Acknowledgement}

The results of the project LO1218 were obtained with financial support from the MEYS of the CR under the NPU I program.

\section{Literature}

Briñas L., M. Zaragaza, Y. Sáenz, F. Ruiz-Larream and C. Torres. $2002 \beta$-lactamases in ampicillin-resistant Escherichia coli isolates from foods, humans, and healthy animals. Antimicrob. Agents Ch. 46: 3156-60.

Cattoir V., L. Poirel, V. Rotimi, C.-J. Soussy and P. Nordmann. 2007. Multiplex PCR for detection of plasmid-mediated quinolone resistance $q n r$ genes in ESBL-producing enterobacterial isolates. J. Antimicrob. Chemoth. 60: 394-397.

Clinical and Laboratory Standards Institute. Performance Standards for Antimicrobial Susceptibility Testing; Twenty Two Informational Supplement. Wayne, Pennsylvania Clinical and Laboratory Standards Institute 2012, 188 p. ISBN 1-56238-786-3.

European Centre for Disease Prevention and Control and European Food Safety Authority; Multi-country outbreak of Salmonella Stanley infections Update. 2012. EFSA Journal 10:2893. [16 pp.] doi:10.2903/j.efsa.2012.2893. Available online: www.efsa.europa. eu/efsajournal.
European Centre for Disease Prevention and Control and European Food Safety Authority: Unusual increase of Salmonella Mikawasima infections in humans. November 2013. Available online: http://www.ecdc.europa.eu/en/publications/Publications/ RRA-unusual-increase-salmonella-mikawasima-cases-in-EU-EEA28-november-2013.pdf.

Guerra B., I. Laconcha, S.M. Soto, M.Á. González-Hevia and M.C. Mendoza. 2000. Molecular characterisation of emergent multiresistant Salmonella enterica serotype [4,5,12:i:-] organisms causing human salmonellosis. FEMS Microbiol. Lett. 190: 341-47. Lewis J.S., M. Herrera, B. Wickers, J.E. Patterson and J.H. Jorgensen. 2007. First report of the emergence of CTX-M-type extendedspectrum $\beta$-lactamases (ESBLs) as the predominant ESBL isolated in U. S. health care system. Antimicrob. Agents Ch. 51: 4015-21.

Myskova P., R. Karpiskova and D. Dedicova. 2013. Salmonellosis outbreaks in the Czech Republic in 2012. Epidemiol. Mikrobiol. Imunol. 62: 59-63.

Ribot E.M., M.A. Fair, R. Gautom, D.N. Cameron, S.B. Hunter, B. Swaminathan and T.J. Barrett. 2006. Standardization of pulsedfield gel electrophoresis protocols for the subtyping of Escherichia coli O157:H7, Salmonella and Shigella for PulseNet. Foodborne Pathog. Dis. 3:59-67.

Synnott M., D.L. Morse, H. Maguire, F. Majid, M. Plummer, M. Leicester, E.J. Threlfall and J. Cowden. 1993. An outbreak of Salmonella mikawasima associated with doner kebabs. Epidemiol. Infect. 111: 473-481. 
